\title{
O QUE FUNDA O LACCO SOCIAL? UM ESTUDO SOBRE A LEI DA LINGUAGEM*
}

\author{
WHAT FOUNDS THE SOCIAL BOND? A STUDY ON THE LAW OF \\ LANGUAGE
}

Alexandre Rubenich *

recebido: 04/2012

aprovado: 06/2012

Resumo: $O$ artigo procura aproximar a questão da linguagem da pergunta pelo laço social. Reconhece que este somente pode ser possível com base em uma concepção de linguagem que não seja refém da tradição metafísica. Nesses termos, o artigo cruza dois horizontes hermenêuticos distintos, a saber, a noção do acordo, que possui sua sede no problema da linguagem, e o conceito de ius gentium, que, embora de origem romana, foi reelaborado na segunda escolástica, dando origem ao Direito Internacional. Estes dois conceitos, entretanto, vão se chocar diretamente com as ideias de natureza humana e de contrato social, de sorte que procuramos problematizá-las desde os seus fundamentos, a fim de apontar o seu embaraço frente à diferença radical.

Palavras-chaves: Hermenêutica, Linguagem, Direito de Gentes.

Abstract: This article seeks to approach the issue of language of the question by the social bond. It recognizes that this can only be possible based on a conception of language that is not hostage to the metaphysical tradition. In these terms, the paper crosses two distinct hermeneutic horizons, namely, the notion of agreement, which has its basis in the problem of language, and the concept of ius gentium, which, though of Roman origin, was reworked in the second scholasticism, giving rise to International Law. These two concepts, however, will collide directly with the ideas of human nature and social contract, so we seek to discuss them from their foundations in order to point their embarrassment in relation to the radical

* Alexandre Rubenich. Mestre em Filosofia. Doutorando PPG-Filosofia Unisinos.
BolsistaCapes/Prosup.em@il: alexandrerubenich@hotmail.com

Problemata: R. Intern. Fil. Vol. 03. No. 01. (2012), pp. 144-176

ISSN 1516-9219. DOI: http://dx.doi.org/10.7443/problemata.v3i1.12210. 
difference.

Key-words: Hermeneutics, Language, People's Rights.

\section{I- Introdução}

A discussão em torno do fundamento do laço social que intentamos desenvolver aqui procura realizar uma aproximação entre a noção do acordo, que nasce no interior do problema da linguagem, e o conceito de ius gentium, que tem sua origem no direito romano, mas que encontra sua determinação precisa junto ao pensamento de Francisco de Vitória ${ }^{1}$.

Levantamos a hipótese de que a questão da linguagem vem chocar-se com o conceito de natureza, de sorte que o não esclarecimento desse termo impede a compreensão do homem como um bios politikós, segundo a precisa definição do Estagirita (ARISTÓTELES, [s.d.], p. 9). Nesses termos, a redução do homem ao biológico, ou, quiçá, a uma pretensa natureza humana, vai ao encontro do destino da tradução/traição dos conceitos gregos de bios, zoé, psyké e phýsis para o latim vita, animale, anima e natura. Ora, como veremos, a latinização dos conceitos gregos acabam por passar por cima do caráter incontornável da linguagem como o acontecimento que funda propriamente a condição humana.

A par disso é que pretendemos mostrar as consequências dessa interpretação, que ao esquecer que o acordo é lei simbólica que opera antes de qualquer positivação, acabou por nos conduzir, na modernidade, ao regime do contrato social, ao passo que o ius gentium, na época em que fora proposto por Vitória procurou justamente recuperar a noção do acordo como um meio possível para assegurar o laço social entre as nações.

\section{II- Acordo ou convenção?}


Segundo os estudiosos da cultura greco-romana John Scheid e Jesper Svenbro (2010), encontramos na narrativa mítica e na especulação filosófica empreendida pelos gregos e romanos a dupla presença dos temas da linguagem e da fabricação do social em meio à ideia de que se constituem a partir da prática da tecelagem. Trata-se, assim, de um entrelaçamento [symploké], que, em um movimento único, enlaça os fios do discurso, constituindo o socius. Um exemplo claro dessa relação se descobre nas analogias que Platão utiliza em seu texto Político (278b), quando, ao tratar do tema da definição do político em sua distinção para com o do filósofo, toma como metáfora o "entrelaçamento" que é preciso ocorrer para que o conhecimento das letras pelas crianças seja possível. Já no Sofista (262c) aparece o problema do lógos, e novamente Platão, a fim de defini-lo, dirá que seu evento depende do "entrelaçamento" das palavras, ou seja, da combinação entre verbos e nomes, rhema e onoma. A questão do "entrelaçamento" também está presente, conforme esses autores ressaltam, na instituição do casamento, ou seja, na "união" matrimonial, que surge como um elemento constitutivo da cidade: “(...) a palavra symploké designa ao mesmo tempo a união física dos esposos e o entrelaçamento - metafórico ou não - dos fios do tecido" (SCHEID; SVENBRO, 2010, p 34).

Com efeito, por intermédio de tais exemplos podemos identificar a proximidade semântica entre as palavras entrelaçamento, combinação, conjunção, união, conjugação, a fim de reconhecermos que se trata, em todos esses casos, da questão do acordo, seja na constituição do lógos, seja na possibilidade da pólis. A par disso, torna-se importante sublinharmos que pensamos o acordo naquele sentido que Heidegger e Gadamer identificam em Aristóteles quando, em seu $D a$ Interpretação, está tratando do discurso em meio à discussão do sýmbolon. Nesta junção e costura reside, segundo 
Heidegger, um acordo, de sorte que no acontecimento do símbolo se encontra a condição de possibilidade do discurso. Devido às implicações do que aqui vem à luz na posição destes filósofos, é que recortamos as seguintes passagens²:

1) O nome é um som que possui significado estabelecido somente pela convenção, sem qualquer referência ao tempo, sendo que nenhuma parte dele tem qualquer significado, se considerado separadamente do todo [Grifo nosso, utilizado para marcar a dificuldade da tradução] $]^{3}$.

2) Um nome tem este ou aquele significado por convenção. Nenhum som é naturalmente um nome: converte-se em um tornando-se um símbolo ${ }^{4}$.

3) Aristóteles diz: o discurso é o que é, ou seja, ele forma um círculo de compreensibilidade [Verständlichkeit], se há a genesis de um sýmbolon, se acontece um sermantido-junto [Zusammengehaltenwerden], no qual ao mesmo tempo reside um acordo [Übereinkommen] ${ }^{5}$.

4) As palavras surgem a partir daquele acordo essencial [wesenhaften Ubereinkunft] dos homens entre si, segundo o qual eles são abertos em sua convivência para o ente que os circunda. $\mathrm{O}$ ente sobre o qual eles podem concordar e ao mesmo tempo não concordar no particular. Somente sobre a base dessa concordância essencial originária o discurso é possível em sua função essencial, no semaínein, no dar-a-compreender do que é compreensível 6 .

5) A convenção, pela qual os sons da linguagem ou os signos da escrita chegam a significar algo, não é um acordo sobre um meio de entender-se - isso pressuporia, de todos os modos, a existência da linguagem -, mas é o haver chegado ao acordo, sobre o que se fundamenta a comunidade entre os homens e em seu consenso sobre o que é bom e correto. Pois bem, os gregos se inclinaram a considerar o que é bom e correto, a que eles chamavam de $n o m o i^{7}$.

6) Numa comunidade linguística real não nos pomos 
primeiro de acordo, mas estamos já sempre de acordo, como o mostrou Aristóteles. É o mundo que se nos apresenta na vida comum, que abrange tudo, e sobre o qual se produz o entendimento ${ }^{8}$.

Por conseguinte, é na aproximação da questão do acordo presente na constituição do lógos a partir da junção de onoma e rehma que se descobre que o discurso humano está para além de toda phoné e, portanto, define-se como um acontecimento que não se reduz ao âmbito da phýsis. De igual modo, encontramos no mesmo horizonte de significação do acordo o fundamento para o nómos, no sentido da lei. Não é por acaso, então, que essa relação aparece justamente quando Aristóteles em sua Política está definindo o existente humano como um ser capaz de fala (zoõn lógon echón), mas que em sua recepção latina soou para nós no sentido estrito de um animal rationale:

(...) o homem é o único animal que tem o dom da palavra. E mesmo que a mera voz sirva para nada mais do que uma indicação de prazer ou de dor, e seja encontrada em outros animais (...), o poder da palavra tende a expor o conveniente e o inconveniente, assim como o justo e o injusto. Essa é uma característica do ser humano, o único a ter noção do bem e do mal, da justiça e da injustiça. E é a associação de seres que têm uma opinião comum acerca desses assuntos que faz uma família ou uma cidade 9 .

Se nos detivermos por alguns instantes naquilo que o sentido do texto de Aristóteles indica, conquistamos o horizonte a partir do qual o fenômeno da linguagem poderá ser visto de uma maneira mais próxima da realidade grega, e não como um simples instrumento do pensamento, tal como nós, os hodiernos, estamos acostumados a entendê-la. Igualmente, nesta passagem identificamos o cruzamento da linguagem com a lei e, nesse ínterim, a constituição do tecido social como fundação de um ethos. A polidez no dizer relaciona-se, assim, com o 
estabelecimento de uma camada ética que assegura e protege o socius.

Heidegger ${ }^{10}$, por seu turno, tem claro o quão problemático é a tradução da zoé grega para o animale latino, de sorte que prefere preservar a significação ampla do ser-vivo, o que permite visualizar a distinção que existe entre nós e os animais, pois na categoria do ser-vivo, o ser-animal é uma possibilidade entre outras ${ }^{11}$. Entretanto, o filósofo alemão faz, em seguida, uma ressalva decisiva: conduzir as coisas nesses termos, ou seja, distinguindo o homem do animal e das plantas é permanecer refém ainda da definição metafísica do homem como um homo animalis, de sorte que se torna urgente retirar o existente humano desse contexto, a fim de conquistarmos o horizonte próprio do sentido do seu ser. Com efeito, uma maneira de fazer isto Heidegger encontra na possibilidade de tradução da phýsis. Traduzida normalmente por "natureza", cuja palavra vem do latim natura, significando nascer, surgir, crescer, a phýsis não se reduz a esta significação, mas a engloba. Nesses termos, Heidegger dirá que a phýsis é "a vigência autoinstauradora do ente na totalidade", querendo dizer com isso que o entendimento do homem para com aquilo que é passa por seu sentido, de saída, no trato com as coisas. Assim, ele não precisa falar expressamente sobre as coisas, a fim de que elas sejam compreendidas, mas ser homem significa já sempre trazer $\mathrm{o}$ vigente à enunciação.

Légein, o falar, o "trazer à fala" significa, para os gregos, conforme sustenta Heidegger (1983, p. 41), desencobrir [Entbergen]. A phýsis, portanto, segundo o filósofo alemão, é descoberta por intermédio do lógos, visto que a vigência das coisas possui a tendência a se esconder, como anunciou previamente Heráclito (Ibid., p. 40). Tendo isso em vista, faz-se imprescindível o reconhecimento de que o homem não é o detentor da linguagem, e sim o contrário, é a linguagem que o possui, porquanto o ser o interpela. A relação que acontece entre 
mundo e linguagem é uma relação que se estabelece, então, de saída, pelo ser, de sorte ao existente humano caber a guarda ou o cuidado da verdade do ser. Como esse velar pela verdade, ou melhor, esse velar pelo desvelar se dá no âmbito da linguagem, Heidegger (1976, p. 323) dirá que a linguagem é a morada do ser. Porém, uma vez que a verdade, em Heidegger, deve ser pensada no sentido do como hermenêutico-existencial [existenzial-hermenetische "Als"], e, portanto, como desencobrimento do ser como ente, e uma vez que a verdade nesse sentido compreende o ser como tempo, a morada do ser, como um lugar onde o ser pode ficar e permanecer, é a mesma linguagem que chega a dizer que as coisas são e que o ser-aí é no modo do presente. O ser-aí vive em uma compreensão de ser que compreende mundo, ou, em palavra distinta, o ser-aí vive a compreensão do ser e, por isso, constitui mundo.

A lembrança de que não somos os senhores da linguagem podemos encontrar prefigurada no pensamento do Estagirita quando ele enuncia que a capacidade de fala que possui o existente humano é um dom, ou seja, é algo que somente pertence a nós, porque nos foi oferecido como um presente. Por se tratar de um presente somos colocados, de saída, em uma situação de dívida para com um Terceiro, o que nos leva a pensar no sentido daquilo que está para além do semelhante e que introduz a possibilidade da troca simbólica - troca de palavras, de bens e de mulheres ${ }^{12}$. Essa tese é assumida também por Safouan, onde encontramos que se deve à imagem do semelhante o terceiro termo (Ele), o pronome do ausente, que se representa tanto na forma do Imperador, que detém o livro da dívida, quando na da Providência, que é ausência de sua presença. O terceiro seria, para Safouan (1993, p. 47), o único termo a possibilitar uma relação viável entre o eu e o $t u$, na medida em que por seu intermédio recebemos a garantia de pertencermos a uma comunidade humana. Lebrun (2010, p. 38), por seu turno, ressalta a importância do reconhecimento do 
Terceiro na estruturação da dimensão simbólica quando diz que este está inscrito na ordem da linguagem e em nossa condição de ser falante. $\mathrm{O}$ autor recupera, nesses termos, a posição de Lacan, para quem a função paterna é equivalente à função da linguagem, visto que introduz no infans a capacidade de substituição significante - a competência metafórica (Ibid., p. 18). Conforme o autor, para Lacan o pai é o representante do comércio da Lei da linguagem: "Para habitar o mundo mediatizado pelas palavras, o sujeito teve de consentir em perder o gozo imediato das coisas. Paradoxalmente, a natureza do homem é então ter perdido o natural" (Ibid., p. 29). Em Lacan (1998, p. 279), o reconhecimento do suporte da função simbólica se dá, em suma, no nome do pai, que identifica em sua pessoa, desde os tempos antigos, a figura da lei. O registro Simbólico possui, por sua vez, uma função tão decisiva, um peso tão determinante em nossas vidas, que vale citarmos o psicanalista francês em uma exclusiva passagem do seu texto:

Os símbolos efetivamente envolvem a vida do homem numa rede tão total que conjugam, antes que ele venha ao mundo, aqueles que irão gerá-lo "em carne e osso"; trazem em seu nascimento, com os dons dos astros, senão com os dons das fadas, o traçado de seu destino; fornecem as palavras que farão dele um fiel ou um renegado, a lei dos atos que o seguirão até ali onde ele ainda não está e para-além de sua própria morte; e através deles, seu fim encontra sentido no juízo final, onde o verbo absolve seu ser ou o condena - a menos que ele atinja a realização subjetiva do ser-para-a-morte (LACAN, 1998, p. 280).

Como antecipa, porém, o filósofo grego, o discernimento do Bem e do Mal nasce do poder da palavra. Ora, a prudência na escolha do Bem ou do Mal, que nos alcança somente pela força da palavra, leva-nos a aventar a hipótese de que o acordo, 
ao permitir o nascimento do lógos e, por isso, a criação de uma totalidade de sentido, e, portanto, de uma compreensão, vem operar justamente antes de qualquer convenção. Dizer que nos compreendemos porque falamos, não significa, porém, dizer que a nossa comunicação é livre de mal-entendidos, e sim que cada mal-entendido garante à compreensão a singularidade de uma escuta. Ou seja, o que compreendemos a cada vez e no mais das vezes permite sermos nós mesmos, ou, nas palavras de Heidegger, um ser-próprio [Selbswelt] que, ao compreender ser, de saída e de imediato, nos constitui como um ser-no-mundo [In-der-Welt-Sein]. De acordo com esta posição, Heidegger é esclarecedor: mundo é o "na totalidade" ["im Ganzen"], de maneira que estamos sempre a caminho deste, em função da finitude [Endlichkeit] que nos concerne. Essa finitude, dirá o filósofo, é o modo fundamental de nosso ser e como tal ela nos singulariza (HEIDEGGER, 1983, p. 8). Para Heidegger, portanto, enquanto o ser do mundo possui o caráter de se mostrar a si mesmo, o ser da vida possui a possibilidade de falar da existência de modo tal que ela se mostre mediante o falar: "O ser do mundo e o ser da vida mantém uma relação totalmente específica mediante o ser do falar" [Sein des Sprechens] (HEIDEGGER, 1994, p. 44). A postura metodológica assumida pelo filósofo alemão, a fim de dar conta da especificidade do seu campo de investigação, a saber, o que ele nomeará de vida fática ou facticidade, a fim de se distanciar da determinação metafísica do homem como ratio, exigirá dele a prudência de partir, para a configuração dos existenciais do ser-aí, da linguagem. O ponto de partida, em última análise, para o empreendimento daquilo que, posteriormente, em Ser e Tempo, ele nomeará de ontologia fundamental, mas que vem expresso, anteriormente, como hermenêutica da facticidade, é a linguagem. Em outros termos, trata-se da pergunta pelo sentido do ser, que como tal somente se realiza porque o ser-aí compreende ser a partir do tempo presente. Porque diz "ser", o 
ser-aí o interpreta como "presente", muito embora sua relação com este já tenha sido aberta e experienciada em um modo distinto, a partir de uma temporalidade também distinta, na medida em que ele é, de saída e de imediato, ser-no-mundo [Inder-Welt-sein $]^{13}$.

\section{III- Do acordo ao contrato}

Devemos tentar agora uma compreensão do que teria conduzido esta comunidade humana, que fixava suas relações sociais por intermédio do acordo, do penhor da palavra falada, para um regime contratual. Procuraremos visualizar, assim, que os pensadores que levantam a hipótese do pacto social ou da teoria do contrato, são os mesmos que creditam que os homens teriam existido algum dia em um estado de natureza, e que a passagem para a Sociedade somente teria acontecido por um ato de vontade, em que todos decidiriam em uma consonância de vozes a sair da barbárie e assegurar sua sobrevivência, nem que para isso devessem alienar sua liberdade. De igual forma, veremos que faz parte desse mesmo conjunto de argumentos a ideia de uma origem natural da linguagem. Partamos, enfim, da linguagem, de sorte a reconhecermos com Derrida que, seja em Rousseau, seja em Hobbes, o que existe é uma prevalência da $v o z$, o que acaba determinando toda uma maneira de se conceber o homem, que de maneira alguma dá conta de sua verdadeira condição humana ${ }^{14}$.

Localizamos em dois textos de Rousseau a sua tomada de posição frente à questão da gênese da linguagem. Seja em seu Discurso sobre a origem e os fundamentos da desigualdade entre os homens (1754) ou em seu Ensaio sobre a origem das 
línguas (1781), o filósofo francês procura retirar o nascimento da linguagem do domínio do sobrenatural, com o intuito de reconduzi-la para o interior da natureza e, assim, postular que se trata de uma invenção. De acordo com Rousseau, é a própria natureza que, em algum momento, realiza uma espécie de torção, de forma que em um único movimento acaba por retirar o "homem" de um estado em que as suas necessidades eram satisfeitas de imediato, em que vigorava uma paz plena e uma tranquilidade sem precedentes. Nesses termos, o seu Discurso parte do reconhecimento da dificuldade de pensar o que teria tornado necessário a invenção da língua ${ }^{15}$. É assim que o filósofo começa, nesse momento, a problematizar as diferentes justificativas para o início da linguagem, sem, contudo, obter um resultado positivo frente às dificuldades apontadas. É justamente para dar conta dessas questões levantadas aqui que Rousseau irá escrever o seu Ensaio. Com efeito, pergunta-se o filósofo no Discurso: "A primeira que se apresenta será imaginar como elas puderam tornar-se necessárias, pois, não tendo os homens qualquer correspondência entre si, nem necessidade alguma de tê-la, não se conceberia nem a necessidade dessa invenção nem a sua possibilidade se não fora indispensável" (ROUSSEAU, 1922, p. 26). Para Rousseau, nesse sentido, a primeira língua do homem, a língua mais universal, é o grito da natureza. Posteriormente, dirá ele, quando as ideias propriamente humanas começaram a se desenvolver, os homens procuraram uma multiplicidade maior de sinais. Nesse instante, expandem-se as inflexões da voz e se juntam a ela os gestos. Mas estes últimos, contudo, por indicarem apenas os objetos presentes, acabam por tornar necessária sua substituição pela articulação da voz. Porém, reconhece Rousseau que uma substituição como essa somente se tornou possível por conta de um consentimento comum. Um acordo como esse, por sua vez, apenas poderia ter sido realizado por intermédio da palavra, o que nos deixa a seguinte questão em 
aberto: como é que a palavra se torna necessária, para estabelecer o seu uso, se apenas agora poderíamos nomeá-la palavra? Em um tom de desabafo, Rousseau pondera:

(...) da impossibilidade quase demonstrada de terem podido as línguas nascer e estabelecer-se por meios puramente humanos, deixo, a quem o desejar, empreender a discussão desse problema difícil de saber o que foi mais necessário - a sociedade já organizada quando se instituíram as línguas, ou as línguas já inventadas quando se estabeleceu a sociedade (ROUSSEAU, 1922, p. 34).

É deste preciso ponto que o seu Ensaio vem ao nosso encontro como uma possível resposta.

Rousseau inicia o seu texto reconhecendo, assim como procedeu Aristóteles antes dele, que é a palavra que distingue os homens dos animais. Além disso, toma a palavra como a primeira instituição social, mas encontra a sua causa tão somente na natureza. A necessidade de comunicação lhe teria advindo em função do reconhecimento do outro como um ser sensível. Nesses termos, mais importante do que a aptidão fisiológica para emitir e articular sons, Rousseau a encontra na necessidade de comunicação a partir do momento em que se dá o reconhecimento do semelhante ${ }^{16}$. Para o filósofo francês há dois meios pelos quais se torna possível agir sobre os sentidos do outro, a saber, pelo movimento do gesto e pela voz, sendo ambos comportamentos naturais. Contudo, o gesto permanece sendo a linguagem mais expressiva, muito embora por seu intermédio nos limitemos apenas ao que se apresenta diante dos nossos olhos. Com a possibilidade da voz e de sua articulação ultrapassamos essa limitação e passamos a comunicar ideias também abstratas: "A língua de convenção só pertence ao homem e esta é a razão por que o homem progride, seja para o 
bem ou para o mal, e por que os animais não o conseguem" (ROUSSEAU, 1973, p. 169).

Rousseau também considera que a primeira invenção das palavras se deve muito mais às paixões da alma do que propriamente à necessidade, porquanto o efeito natural destas consiste, antes, em separar os homens do que em aproximá-los: "Não é a fome ou a sede, mas o amor, o ódio, a piedade, a cólera, que lhes arrancaram as primeiras vozes"; é por isso, considera o filósofo francês, que as primeiras línguas deviam ser cantadas (Ibid., p. 170). Assim, para Rousseau, antes mesmo que os homens pudessem conhecer as coisas em sua verdadeira identidade, o seu sentido era figurado, de forma que para a primeira linguagem exige-se o uso de uma linguagem metafórica. Porém, para que a invenção da linguagem pudesse seguir se desenvolvendo também precisava operar aí e, talvez de maneira decisiva, segundo o filósofo francês, as necessidades naturais, porquanto os homens deviam resguardar os meios de sua sobrevivência. Sobre esta relação cabe uma citação do texto de Rousseau, que embora um pouco extensa, permite-nos encontrar o suporte da argumentação do seu ensaio, a saber, aquele em que reconhece que o momento de ruptura do estado de natureza deveria ser algo que, embora natural, talvez o excedesse. Ou seja, tratava-se, segundo Derrida (op. cit., p. 183), de um modelo de explicação de saída da natureza para fora de si, absolutamente natural e, de igual forma, absolutamente artificial:

Supondo uma eterna primavera na terra; em todos os lugares, supondo água, gado, pasto; suponde os homens, saindo das mãos da natureza, e, depois de dispersar-se num tal meio - não posso imaginar como um dia renunciariam à sua liberdade primitiva $\mathrm{e}$ deixariam a vida isolada e pastoril, tão conveniente à sua indolência natural, para desnecessariamente imporse a escravidão, os trabalhos e as misérias inseparáveis do estado social. Aquele que quis que o homem fosse 
sociável pôs o dedo no eixo do globo e o inclinou sobre o eixo do universo. Com esse leve movimento, vejo a face da terra mudar-se e decidir-se a vocação do gênero humano; ouço ao longe gritos insensatos de uma louca multidão; vejo nascerem as artes, as leis e o comércio; vejo os povos formarem-se, espalharem-se, sucederemse como ondas do mar; vejo os homens reunidos em alguns pontos de seu território para aí se devorarem mutuamente e transformarem o resto do mundo num tremendo deserto, monumento digno da união social e da utilidade das artes (ROUSSEAU, 1973, p.185).

De posse desta orientação é que somos introduzidos agora junto ao horizonte da questão da linguagem em Hobbes. Entretanto, esta não nos ocupará de maneira exaustiva, de sorte que aqui preferimos apenas nos manter ao nível daquilo que ele nos apresentou no capítulo IV do seu Leviatã. Nesse pequeno texto, embora de reconhecida importância, encontramos que a maneira pela qual Hobbes pensa a linguagem o aproxima do nominalismo, na justa medida em que aponta para o caráter irredutível da convenção em que as coisas chegam a ser nomeadas. Além disso, Hobbes considera neste lugar a invenção da linguagem pelo lado de sua utilidade, uma vez que permitiria ao homem registrar os seus pensamentos, recordar, conversar. Para Hobbes, então, deve-se ao caráter utilitário da linguagem a possibilidade de haver entre os homens o Estado, a sociedade, o contrato. Porém, o filósofo inglês, diferente de Rousseau, não retira a origem da linguagem de um domínio transcendental, muito embora reconheça que todo conhecimento somente é possível com base nos sentidos. Nesse ínterim, considera Hobbes, se por um lado Deus ensinou a Adão a designar as criaturas que the colocava diante da sua visão, por outro lado, apenas a experiência e o convívio lhe teria tornado possível chegar a um nível de linguagem que ultrapassaria a dimensão em que Deus o havia colocado. Vale dizer ainda que para Hobbes, o uso da linguagem consiste em passar do discurso 
mental para um discurso verbal, ou seja, a linguagem, em última análise, é para o filósofo inglês, expressão do pensamento, o que ele lê no sentido da palavra grega lógos, porquanto, para os gregos, segundo Hobbes, o lógos designava tanto linguagem quanto razão.

De posse, portanto, desses dois pontos de vista, vimos que tanto num filósofo quanto no outro está presente a ideia de que o homem teria existido em um estado de natureza, que somente veio a ser ultrapassado a partir do momento em que houve a invenção da linguagem por intermédio de uma convenção. Esta, por sua vez, mediante o uso da palavra, fundou o socius. $\mathrm{O}$ socius, nesses termos, encontra seu fundamento desde o momento em que os homens, por ação de sua vontade livre, resolveram contratar, firmando um pacto que assegurasse o seu cumprimento por parte de todos. É assim que tanto em Hobbes quanto em Rousseau será introduzido a questão do contrato social. Passamos, em seguida, a uma breve discussão do que se apresenta em um texto e outro, a saber, o Contrato social, em Rousseau, e o Leviatã, em Hobbes, a fim de traçarmos os pontos comuns de suas argumentações.

Rousseau dá início à sua escritura reconhecendo que o homem nasce livre. Contudo, assevera, que a ordem social, ainda que seja um direito sagrado, funda-se, não na natureza, pois esta possui uma base instintiva, e sim em convenções. Para Rousseau, a única sociedade que poderia ser reconhecidamente natural é a família, pois a relação entre pais e filhos possui um vínculo necessário. Porém, a união da família apenas se dá por convenção. A primeira lei que faz parte da natureza humana tem sua observância, portanto, no instinto de conservação. Encontramos na família, segundo Rousseau, o modelo originário das sociedades políticas, sendo o pai a imagem do chefe e a dos filhos a imagem do povo. De acordo com o filósofo francês, apenas quando os homens já não encontram mais os meios de sua conservação no estado de natureza é que 
passam a deliberar sobre uma possível associação:

As cláusulas desse contrato são de tal modo determinadas pela natureza do ato, que a menor modificação as tornaria vãs e de nenhum efeito, de modo que, embora talvez jamais enunciadas de maneira formal, são as mesmas em toda parte, e tacitamente mantidas e reconhecidas em todos os lugares, até quando, violando-se o pacto social, cada um volta a seus primeiros direitos e retoma sua liberdade natural, perdendo a liberdade convencional pela qual renunciara àquela ${ }^{17}$.

Conforme sustenta ainda Rousseau, todas essas cláusulas podem ser reduzidas a apenas uma, a saber, a alienação total de cada associado, com todos os seus direitos, à comunidade. Esse ato, para Rousseau, produz um corpo moral e coletivo, constituindo um eu comum. $\mathrm{O}$ ato de associação corresponde a um compromisso entre o público e os particulares, de sorte que cada indivíduo ao contratar compromete-se, segundo Rousseau, em uma dupla relação: “(...) como membro do soberano em relação aos particulares, e como membro do Estado em relação ao soberano" (ROUSSEAU, 1763, p. 20). Por fim, vale dizer que, para Rousseau, a passagem do estado de natureza para o estado civil substitui na conduta do homem o instinto pela justiça, configurando-lhe em suas ações a moral. O que o homem perde pelo contrato social é a liberdade natural, ao passo que ele ganha a liberdade civil e, com isso, a propriedade dos seus bens. Somente no momento em que se acede ao estado civil, pondera ainda Rousseau, o homem ganha sua liberdade moral, tornando-o senhor de si mesmo.

Como afirma Rousseau, uma vez que com o pacto social constituímos uma pessoa pública, trata-se agora de lhe dar, pela legislação, movimento e vontade. O filósofo francês reconhece que muito embora toda justiça emane de Deus, os homens 
possuem uma grande dificuldade de recebê-la, de modo que se torna necessário passarmos a instituir nossas próprias leis e governo: "São, pois, necessárias convenções e leis para unir os direitos aos deveres, e conduzir a justiça a seu objetivo" (Ibid., p. 47). Dessa forma, no estado civil os direitos dos homens dependem exclusivamente da Lei. Para Rousseau, por tratar-se de algo que visa o todo, o povo em sua unidade e totalidade, o objeto das leis é sempre geral. O ato que recebe o nome de lei é estatuído por uma vontade geral que visa uma matéria geral. Portanto, tal lei considerará os súditos como corpo e suas ações como abstratas. Por último, importa dizer com Rousseau, que as leis são propriamente as condições da associação civil, sendo o povo que se submete a ela o seu autor (Ibid., p. 50).

O ponto de partida em Hobbes (1929), para analisar a passagem do estado de natureza para o estado civil nos parece distinto daquele empregado por Rousseau. E isso porque, consoante ao filósofo inglês, tal travessia somente ocorre devido à discórdia natural dos homens contra todos os homens. Estes, por sua vez, por se encontrarem apartados de um poder comum, capaz de criar uma unidade política, descobrem-se de saída, em condição de guerra, o que faz com que todos os homens sejam inimigos. Aqui não opera ainda as qualidades da justiça e da injustiça, que apenas se inscrevem quando há a constituição de uma sociedade civil. Com efeito, para Hobbes, apenas as paixões da alma, como o medo da morte e o desejo do que é necessário, são capazes de mobilizar nos homens as forças que o conduziriam à paz. Uma vez que a razão sugira normas de paz, estas viabilizariam aos homens chegar a um acordo. A essas normas, por seu turno, Hobbes nomeia de leis da natureza. O direito de natureza, ou jus naturale, é, conforme Hobbes, a liberdade que os homens possuem de usar seu poder para preservação de sua vida, ao passo que a lex naturalis é uma regra geral, mediante a qual se proíbe ao homem fazer algo que possa destruir sua vida, ou privá-lo dos meios necessários para 
preservá-la (Ibid., p. 99). Hobbes, nesses termos, distingue jus e lex, identificando o primeiro ao direito que "(...) consiste na liberdade de fazer ou de omitir, ao passo que a lei determina ou obriga a uma dessas duas coisas" (Ibid. p. 99). Se, como propõe Hobbes, a condição humana é uma condição de guerra, em que cada um governa por sua própria razão, segue-se daí que todo homem possui o direito de todas as coisas. Da lei fundamental da natureza, por intermédio da qual se ordena que todos os homens procurem a paz, deriva, portanto, uma segunda lei: "Que um homem concorde, quando os outros também o façam, e na medida em que tal considere necessário para a paz e para a defesa de si mesmo, em renunciar a seu direito a todas as coisas (...)" (Ibid., p. 100). A esta transferência mútua de direitos é o que Hobbes denomina contrato. Se uma das partes se compromete, contudo, em assumir o contrato a posteriori, e a parte contratante confia na posição deste, nesse caso, o contrato se chama pacto ou convenção. Um pacto, nesses termos, é um ato de vontade. Contudo, a sua observância não pode ser cumprida apenas pela força das palavras, devendo-se seguir a elas o medo. Apenas pela paz, fundamental à conservação da vida, cria-se, segundo o filósofo inglês, o pacto social, de sorte que por seu intermédio o homem é introduzido, finalmente, em uma ordem dita moral. Diferente dos animais que cooperam entre si naturalmente, os homens, entretanto, por seu egoísmo, apenas entram em acordo artificialmente, ou seja, pela convenção. $\mathrm{O}$ contrato, assim, é estabelecido entre os membros do mesmo grupo que, entre si, concordam em renunciar ao direito natural, transferindo-o a um terceiro, que os representará, tornando-se, a partir desse momento, o responsável por assegurar a paz à comunidade dos homens, que agora, finalmente, será nomeada de sociedade civil. Legislador máximo, o soberano, em Hobbes, é absoluto, de maneira que não se submete a lei alguma, devendo sua obediência somente a Deus. 
Como podemos acompanhar até aqui, os temas são comuns em ambos os filósofos, muito embora eles tenham as suas especificidades conceituais. Entretanto, para nós, o que interessava era mostrar que por trás de toda noção de um estado de natureza, vinculava-se uma concepção do homem preso a uma ideia de natureza humana, na qual prevalecia a hipótese de que o homem já existia, muito embora independente das palavras e sem uma sociedade constituída. Em estado de natureza! Mas é isto possível? Como falar de um estado em que o homem não havia estabelecido ainda a Cultura, porquanto lhe faltavam as palavras e, uma vez sem estas, perguntamos como teria sido possível a eles, sozinhos, descobrirem o outro, reconhecê-lo como semelhante e compreendê-lo em sua paixão pela vida? Como podemos pressentir, faltam aí palavras, e o estado de natureza não pode ser nada mais do que uma hipótese construída por filósofos. Se esses são os temas, vamos procurar encontrá-los nos seus primeiros promotores, antes, contudo, de que se houvesse constituído a ideia do contrato. Passemos em revista o pensamento de Tomás de Aquino e Aristóteles sobre essas questões, a fim de descobrirmos o que significa o direito natural e no que ele se diferencia do direito positivo. Somente assim poderemos compreender a atitude de Francisco de Vitória na busca do conceito de ius gentium, como um meio possível de assegurar a paz entre as nações e de reconhecer a cultura dos povos arcaicos. No conceito de ius gentium procuraremos encontrar, portanto, o vigorar do acordo para além de toda convenção, no sentido de que nesta existe a prerrogativa de que os homens deveriam se reunir para deliberarem sobre..., a fim de estabelecerem algo, ao passo que com a noção do acordo o que propomos é que os homens já estariam reunidos, de saída, num laço social por força mesma das palavras. Com efeito, a nossa interpretação segue o sentido de que o laço social somente pode ser constituído pela palavra, e, por isso, pelo registro do Simbólico e, nesses termos, pelo lugar da exceção 
que corresponde ao terceiro como representante da Lei. Ora, se há tal registro é somente porque aí impera o domínio da Lei, que ao proibir, instaura o limite e inscreve uma falta. Ou seja, o que não comparece no todo dos entes presentes é, justamente, sua condição de possibilidade.

\section{IV-Do direito natural ao conceito de ius gentium em Vitória}

Tendo em vista que o Aquinate se apóia em Aristóteles para desenvolver suas teses, importa compartilharmos suas posições de modo intermitente. É assim que, na questão 57 da Secunda Secundae da Suma Teológica, o filósofo medievo, ao definir o que seja o direito natural, toma em consideração o que aparece no livro V da Ética a Nicômacos, onde o Estagirita propõe que a justiça política é em parte natural e em parte legal.

Bem, para Aristóteles, a justiça natural diz respeito às coisas que em todos os lugares possuem a mesma força e independem de nossa aceitação, ao passo que a justiça legal depende de convenção. Portanto, de acordo com o filósofo grego, a justiça natural possui um caráter universal, visto que se refere a coisas que não podem ser de outra maneira ${ }^{18}$. Nessa perspectiva, o justo natural está baseado na verdade, na essência das coisas, enquanto que o justo legal depende da doxa. Para o Aquinate, que, para formular as suas teses se apóia em Aristóteles, se o direito, ou o justo, é uma ação adequada à outra com base em um princípio de igualdade, o direito natural corresponderá a algo que é adequado ao homem pela natureza mesma da coisa em questão. Em contrapartida, o direito positivo dirá respeito ao que é adequado somente por convenção ${ }^{19}$. Como quer Aristóteles sobre esse tema, “(...) a justiça é a disposição da alma graças à qual ela se dispõem a fazer o que é 
justo, a agir justamente e a desejar o que é justo" ${ }^{20}$. Ora, uma vez que o ato justo é o meio termo e que o meio termo pressupõe igualdade; e uma vez que a justiça, como prática da excelência moral, se realiza em relação ao próximo, visando o bem dos outros, a justiça deve ser compreendida em Aristóteles como o exercício de uma ação na qual o outro está implicado, de saída, de sorte que nela exige-se o reconhecimento de um semelhante. Portanto, somente porque a justiça acontece entre iguais e, assim, desde o momento em que, pela palavra, no cruzamento da trama e da urdidura, o tecido social é produzido, não pode ser pensada, em Aristóteles, com independência da dimensão ética na qual ela está ancorada. Desta feita, o bemviver depende diretamente do bem-agir em relação ao próximo, na medida em que é justamente esta relação que constituirá e garantirá a morada dos homens.

De posse desses conceitos, podemos avançar agora para aquilo que o Aquinate entende por ius gentium, na medida em que com ele vem introduzir-se um terceiro termo entre o justo natural e o justo legal. Como poderemos observar a seguir, o direito de gentes é um caso exemplar de um direito que diz respeito a todos os homens. Conforme considera o filósofo medievo a respeito dessa questão, o direito de gentes refere-se a algo que é de comum acordo a todos os homens, ainda que não esteja esclarecido se este se deu por convenção ou naturalmente. Nesses termos, trata-se de saber se ele é direito natural, ou, quiçá, direito positivo. De acordo com Tomás de Aquino, tratase, nesse caso, de identificarmos uma distinção de modos. Ou seja, se num primeiro modo o homem compartilha com os animais um direito natural, porquanto, por exemplo, a partir da natureza da coisa mesma, o macho ajusta-se à fêmea, e os pais ao filho para alimentá-lo, num segundo modo, tomando por base as consequências relativas à coisa, o direito da posse de propriedade pode decorrer da conveniência do seu cultivo. É nesse último modo que se revela, pois, o direito de gentes ${ }^{21}$. 
Para estabelecer esse argumento, ressaltamos que o Aquinate se apoiou tanto em Ulpiano quanto em Gayo. Em Ulpiano ele encontra o que segue: "do direito natural, com efeito, assim dito, afasta-se o direito de gentes, porque àquele é comum a todos os animais, e este somente aos homens entre si”. Já, em Gayo: "O que a razão natural constituiu entre todos os homens é observado entre todos os povos, e se chama direito de gentes" 22 .

Por último, cabe estabelecer, então, o significado da lei natural para Tomás de Aquino. É assim que na questão 94 da Secunda Secundae ele considera que a lei natural é algo constituído pela razão, pertencendo à mesma ordem da proposição. Com respeito a ela, o Aquinate pondera que pode ser tomada como um habitus apenas na condição de ser um princípio intelectivo que nos faz discernir o bem do mal. Tendo em vista que a lei pertence ao gênero do preceito e que, além disso, acompanha a natureza do homem, porquanto tem sua sede na razão, o filósofo medievo, para determinar o funcionamento da lei natural, argumenta com base em um paralelismo entre a ordem das verdades teóricas e a das ações. É assim que, partindo de princípios indemonstráveis - axiomas -, chega a estabelecer, na razão prática, que o primeiro princípio da lei é que o bem deve ser feito e o mal evitado:

(...) é inerente ao homem, por primeiro, a inclinação para o bem segundo a natureza que tem em comum com todas as substâncias, isto é, conforme cada substância deseja a conservação de seu ser de acordo com sua natureza. E segundo essa inclinação, pertencem à lei natural aquelas coisas pelas quais a vida do homem é conservada, e o contrário é impedido ${ }^{23}$.

Vale ainda dizer que pertencem à lei natural aquelas coisas às quais o homem se inclina naturalmente, como, por exemplo, o ter de agir segundo a reta razão, visando o bem 
comum. Entretanto, diferentemente da razão especulativa, que trata das coisas necessárias, a razão prática possui seu fundamento nas coisas contingentes, ou seja, no restrito horizonte das operações humanas. Ora, como vimos acima, o conceito de ius gentium faz parte, justamente, desse contexto, muito embora tenha um alcance universal. Torna-se, portanto, premente avançarmos até a segunda escolástica, a fim de averiguarmos junto a Francisco de Vitória a recepção desse conceito, porque a partir de sua aplicação seria possível dar conta das exigências políticas que a descoberta do novo mundo suscitara.

Primeiro vale ressaltarmos a conjuntura em que as teses de Francisco de Vitória foram defendidas. Tratava-se de um momento delicado e ao mesmo tempo dramático na vida dos espanhóis: o encontro com uma alteridade cultural amplamente distante dos modos e costumes da Europa. Com um sistema de crenças distinto, organizações sociais próprias e formas de vida e língua desconhecidos, os índios recém descobertos tampouco eram reconhecidos como seres dignos da natureza humana pelos colonizadores espanhóis. Foi justamente com vistas ao reconhecimento do outro radical que a obra de Francisco de Vitória veio em auxílio, e que a retomada do conceito de ius gentium se tornou uma ferramenta teórica imprescindível. Por um lado, tornava-se necessário justificar a dominação espanhola por intermédio de uma distinção justa entre civilização e barbárie; por outro lado, era decisivo que se pudesse aproximálos das crenças européias, com o intuito de evangelizá-los e educá-los com as letras da cultura cristã. Tendo em vista que a posição aristotélica da escravidão natural se portava como uma chave teórica importante que justificaria a dominação dos índios como seres inferiores, não dotados de uma capacidade racional condizente com a dignidade humana, os teólogos escolásticos procuraram desenvolver teses que tinham como premissa o direito natural, na medida em que sua justificação seria 
corroborada por argumentos metafísicos, de ordem ontológica e antropológica, com respeito a possibilidade de uma implícita normatização de caráter universal, capaz de regular as relações entre os povos: “(...) um conjunto de normas que, enquanto correspondentes à ordem da natureza instituída por Deus, constituem uma base objetiva de valoração moral que deve ser compreendida e compartilhada por todos os homens e por todos os códigos normativos positivos, com independência das diferenças culturais" (PENÃ, 2006). Porém, como indica Penã (2006), centrar a argumentação com vistas ao reconhecimento dos indígenas como seres humanos a partir de uma concepção de natureza humana no mínimo bastante controversa, cuja recepção por parte dos mesmos seria de difícil compreensão, fez também aparecer no discurso dos escolásticos uma noção procedente do direito romano, a saber, o conceito de ius gentium, pois este toma como base certos usos comuns a todos os povos. Esse conceito é importante para a Escolástica espanhola, porque introduz a ideia de uma comunidade universal de direito, cujo solo se funda no acordo, como índice da natureza compartilhada. O ius gentium encontra, portanto, seu ponto de apoio na noção de que existem instituições e normas jurídicas comuns aos povos de todo o mundo. Nesses termos, prevalece a controvérsia em sua possível aproximação com o direito natural:

$\mathrm{O}$ direito de gentes, enquanto direito natural ou algo muito próximo ao direito natural, fornece o fundamento de universalidade e "naturalidade" que legitima a ação e intervenção dos conquistadores ali onde não existe um código positivo comum, apelando simplesmente à constatação do reconhecimento universal de certos princípios e normas, que parece argumento suficiente para inferir seu enraizamento na natureza humana. Por outra parte, enquanto direito positivo, o direito de gentes permite explicar, e até justificar, a existência e vigência de certas instituições, como a escravidão, que não seriam estritamente 
admissíveis ou suscetíveis de fundamentação pela via jusnaturalista (PENÃ, 2006).

Como quer Penã (2006), a ideia de uma comunidade universal dos seres humanos, que não seja apenas moral, mas que possua um amparo jurídico, implica o reconhecimento de um vínculo universal entre os homens, de sorte a garantir a independência de suas crenças e a liberdade de escolha do regime político pertinente a cada sociedade humana. Vitória, desse modo, faz uso dessa argumentação em sua famosa relección De Indis. De acordo com o comentador Urbanoz (1960), a disputa abre-se tendo como motivo os "índios do novo mundo". Sobre isso se propõe a questão sobre os direitos que tiveram os espanhóis pela ocupação e as relações de regime ou governo da autoridade espanhola e da Igreja em sua evangelização e administração espiritual. Vitória, nesses termos, não se opõe à justiça global da conquista e ocupação da América, e sim sobre os fundamentos teóricos sob os quais ela se sustentava. Para sua demonstração, o mestre de Salamanca recorre ao estabelecimento do fundamento último do direito, que consiste na dignidade da pessoa humana como um ser racional. O homem, assim, se constitui em pessoa moral e sujeito capaz de direitos e deveres por sua racionalidade, já que pelo uso de sua faculdade racional e sua consequente liberdade tem o domínio de seus próprios atos e é capaz de eleger livremente seus destinos e de usar das coisas e criaturas inferiores para seus próprios fins ou em benefício próprio. A faculdade racional é, pois, o fundamento formal que outorga ao homem o ser capaz de domínio e de direitos. Devido à dificuldade que vem colocada pelo conteúdo do direito natural, Vitória, segundo Penã (2006), argumenta em termos de direitos e deveres inerentes às relações entre os seres humanos. Ou seja, o teólogo vai chamar a atenção para um direito de sociedade e de comunicação, fundado na participação dos homens em um 
território compartilhado. Para Penã (2006), este direito de sociedade e de comunicação se baseia exclusivamente no direito de gentes. Como esclarece Vitória (1946, p. 196), nem sempre o direito de gentes deriva-se do direito natural, bastando para que ele opere o consentimento da maioria. O que distingue, de modo específico, o direito de gentes, nesse caso, é sua aceitação universal, cuja possibilidade ultrapassa a mera convenção. Uma convenção que viesse suspender esse acordo entre os homens, ou seja, o direito de todos de se aproximarem e estabelecerem trocas, é, segundo Vitória, impossível. Conforme sustenta Penã (2006), isto ocorre porque "(...) o acordo revela implicitamente que todos os indivíduos de todos os povos, como sujeitos racionais, veem intuitivamente o vínculo existente entre essas normas e as exigências fundamentais da vida e das relações humanas". Em outras palavras, com o conceito de ius gentium encontramos um exemplo prático em que vigora a noção do acordo que procuramos sustentar acima. Não é de se estranhar, então, que ele servira justamente para promover a ampliação do socius, reconhecendo a condição humana também àqueles povos considerados bárbaros.

\section{V-Considerações finais}

O caminho que procuramos percorrer nessas linhas nos conduziu por diferentes searas filosóficas. Este expediente se mostrou necessário, visto que nos possibilitou aproximar pensamentos dispersos, separados por um tempo não menos diverso, a fim de apresentarmos o núcleo comum em que grassa uma representação do homem e da linguagem que se reproduz de maneira evidente para nós hodiernos, mas que passa por cima justamente de sua condição humana. Nesta representação perde-se o que há de decisivo e exemplar em nossa condição, a 
saber, o lugar de exceção em que se funda a possibilidade do Simbólico, por intermédio do qual ela se descobre apartada, para sempre, da natureza. Se, por um lado, tentamos encontrar no acordo a condição de possibilidade para o socius; se procuramos encontrar neste um sentido anterior à convenção ou ao contrato; e, ainda, se tínhamos o indício de que o conceito de ius gentium poderia vir ao encontro de nossa tese, tendo sido convocado pelos pensadores da segunda escolástica no momento em que a história da humanidade mais se viu confrontada com a diferença do outro; em contrapartida, devemos reconhecer, agora, que o acordo, como lei simbólica, somente encontra sua possibilidade por conta do que não comparece na sua totalidade/unidade, o que a sua não positividade fornece os indícios.

Com efeito, se os fios que tecem o socius são os mesmos que enlaçam a linguagem; se o símbolo vem justamente unir o disperso, entrelaçando o verbo e o nome para constituir o discurso e fundar o laço social; e, ainda, se a unidade do signo linguístico, para seguir a terminologia de Saussure (2006), não pode ser pensada apartada do caráter duplo do significante e do significado, de uma face sensível (expressão) e de uma face inteligível (conteúdo), é porque, então, como quer Derrida (2008, p. 22), a prevalência da vox determina a interpretação metafísica do ser como presença, ou da subjetividade como presença a si, de sorte que ambos os conceitos estão ancorados em uma pretensa presença eterna (Deus). Como sublinha o filósofo francês, não é por acaso que Heidegger, ao falar da "voz do ser" nos lembra que ela é silenciosa, muda, sem palavra (Ibid., p. 27). Ou seja, que para Heidegger se trata de realizar uma ruptura entre o sentido originário do ser e a palavra, entre o sentido e a voz. O sentido do ser, que Heidegger quer recuperar, ou, quiçá, inaugurar para a história da filosofia, não se deixa jamais reduzir a um simples significado, visto que o ser escapa ao movimento do signo (Ibid., p. 27). Como quer o filósofo 
alemão, se os gregos recolheram, na proximidade constituinte do lógos, a definição da essência do homem, não foi para indicar que a linguagem seria uma capacidade entre outras, mas por se manter nele a caracterização de sua essência, a saber, como o "(...) comportamento, com base no qual apenas o que se presenta como tal se reúne ao redor do e para o homem" (HEIDEGGER, 1976, p. 279). Nesses termos, se formamos mundo porque possuímos linguagem, torna-se no mínimo estranho, para não dizer ingênuo, falar de um mundo que possuiria uma ordem dita natural, apartada do seu registro linguageiro. Sobre esta questão Garcia-Roza é preciso em suas palavras:

(...) a partir do surgimento da linguagem, todos os objetos do mundo passaram a ser significativos. Ao ser através do qual a palavra fez sua emergência - e que foi por ela constituído - chamamos homem. A palavra não fez sua emergência no homem; o homem é um efeito dessa emergência. (...) $\mathrm{O}$ efeito imediato foi uma desnaturalização do corpo, das suas necessidades e dos objetos do mundo, assim como o surgimento de uma nova ordem: a ordem simbólica (GARCIA-ROZA, 1990, p. 16).

Portanto, conforme atesta o teórico da psicanálise, pensar uma ordem fora da linguagem é fazer mitologia, é criar uma ficção sobre um momento na história em que o homem ainda não estava lá para narrar essa experiência. Como a construção dessa ficção não se pode dar senão com o uso das palavras, a ordem natural já se torna, de saída, uma ordem simbólica, de sorte que, porque falamos, enlaçamos o outro na sua diferença e nos ligamos a ele por nossas semelhanças. Em palavras distintas, somente chegamos a dizer "eu" porque o outro já nos precede aí com a sua linguagem, inscrevendo-nos na ordem simbólica e determinando-nos com a sua diferença. A 
diferença, aqui, em última análise, é o terceiro, é a exceção, que estabelece as regras do jogo, a fim de que possamos conviver com o semelhante. Por isso, se chegamos a dizer "eu" e "tu" é porque "nós" já nos encontrávamos aí. Desse modo, há um entre-nós que nos constitui e precede, convocando-nos a reconhecer que o "nó" é o laço, ao passo que o "nós" é o social. Ou, como entendeu Saussure (2006, p. 25): o signo é o social, de maneira que a nossa vontade individual jamais é suscetível de determiná-lo. Como aponta, por fim, Derrida, a respeito da querela entre o simbólico e o natural, a lei natural vem representar a unidade nativa da voz e da escritura como prescritiva, de forma que a primeira fala, como voz interior, possui um caráter de lei, apenas ouvida "(...) na intimidade da presença a si, como voz do outro e como mandamento" (DERRIDA, 2008, p. 21).

Em tom conclusivo, acompanhamos Heidegger sobre a importância de ir às coisas mesmas: "É somente lá onde a linguagem foi degradada a um meio de comunicação e de organização, a saber, junto a nós mesmos, que tudo se dá como se o pensar que surge da linguagem fosse uma mera "filosofia das palavras", que já não toca mais a "realidade próxima da vida" (HEIDEGGER, 1976, p. 280).

Referências

AQUINO, T. Suma Teológica. São Paulo: Loyola, [s.d.], v. 6.

ARISTÓTELES. Política. In: Os Pensadores. São Paulo: Nova Cultural, 1999.

. Da interpretação. In: Órganon. Bauru: EDIPRO, 2005.

Ética a Nicômacos. $3^{\mathrm{a}}$ ed. Brasília: Editora UnB, 2001.

BENVENISTE, E. Problemas de linguística geral I. $4^{\mathrm{a}}$ ed. Campinas: Pontes, 1995.

BORGES DE MACEDO, P. E. O direito de gentes: entre o direito natural $e$ o direito positivo. Ago. 2007. http://jus.com.br/revista/texto/11542/o-

Problemata - Rev. Int. de Filosofia. Vol. 03. No. 01. (2012). pp.144-176

ISSN 1516-9219 
direito-das-gentes-entre-o-direito-natural-e-o-direito-positivo.

DERRIDA, J. Gramatologia. São Paulo: Perspectiva, 2008.

. Margens da filosofia. Porto: Rés, [s.d.].

GADAMER, H-G. Warheit und Methode. Tübingen: J. C. B. Mohr, 1986.

GARCIA-ROZA, L. A. O mal radical em Freud. $3^{\mathrm{a}}$ ed. Rio de Janeiro: Jorge Zahar, 1990.

HEIDEGGER, M. Einführung in die Phänomenologische Forschung. Frankfurt am

Main:Vittorio Klostermann, 1994. . Die Grundbegriffe der Metaphysik: Welt, Endlichkeit, Einsamkeit. Frankfurt am Main:Vittorio Klostermann, 1983.

. Wegmarken. Frankfurt am Main:Vittorio Klostermann, 1976.

HOBBES. Leviathan. Oxford: Clarendon Press, 1929.

LEBRUN, J-P. O mal-estar na subjetivação. Porto Alegre: CMC, 2010.

LACAN, J. Escritos. Rio de Janeiro: Jorge Zahar, 1998. . O Seminário, Livro 3. Rio de Janeiro: Jorge Zahar, 2008.

LEVI-STRAUSS. As estruturas elementares do parentesco. $5^{\mathrm{a}}$ ed. Petrópolis: Vozes, 2009.

MAUSS, M. Sociologia e antropologia. São Paulo: Cosac \& Naify, 2003.

MERLEAU-PONTY, M. A prosa do mundo. São Paulo: Cosac \& Naify, 2002.

PENÃ, J. Universalismo moral y derecho de gentes en Francisco de Vitoria. Rev. estud. hist.-juríd. [online], 2006, n.28 [citado 2012-0209], pp. 289-310. Disponível em:

http://www.scielo.cl/scielo.php?script=sci_arttext\&pid=S0716$54552006000100008 \& \operatorname{lng}=$ es\&nrm $=$ iso.

PLATÃO. Sofista. In: Diálogos I. Bauru: EDIPRO, 2007. . Político. In: Diálogos IV. Bauru: EDIPRO, 2009.

RICOEUR, P. Teoria da interpretação: o discurso e o excesso de significação. Lisboa:

Edições 70, 2009.

ROUSSEAU, J-J. Du contrat social, ou principes $d u$ droit politique.Amsterdam: M. M.

Rey,1763.

. Ensaio sobre a origem das línguas. In: Os Pensadores. São Paulo: Abril

Cultural, 1973.

. Discours sur l'origine et les fondements de l'inégalité parmi les hommes. New York: Oxford University Press, 1922.

SAFOUAN, M. A palavra ou a morte: como é possível uma sociedade humana?

Campinas: Papirus, 1993.

SAUSSURE, F. Curso de linguística geral. São Paulo: Cultrix, 2006. 
SCHEID, J; SVENBRO, J. O oficio de Zeus: mito da tecelagem e do tecido no mundo

grego-romano. Porto Alegre: CMC, 2010.

URBANOZ, T. Obras de Francisco de Vitoria. Madrid: editorial católica, 1960.

VITÓRIA, F. Derecho natural y de gentes. Buenos Aires: Emecé, 1946.

\section{Notas}

$1 \mathrm{O}$ presente trabalho foi elaborado como requisito parcial para a disciplina Seminário Avançado, ministrada pelo Prof. Dr. Alfredo Culleton e inserese em uma pesquisa mais ampla, que diz respeito à produção de minha tese doutoral.

Francisco de Vitória, célebre dominicano que viveu entre os anos 1490 e 1546, foi o padre do renascimento teológico espanhol e de todo o movimento espiritual da segunda escolástica (séculos XVI e XVII). É considerado, além disso, o fundador do Direito Internacional moderno, assim como o inspirador de um sistema de colonização pacifista e humanitário. Entre suas principais obras encontram-se as famosas Relecciones, cuja primeira edição data de 1557.

2 As teses aqui defendidas são assumidas também pela hermenêutica de Paul Ricoeur. Encontramos o filósofo francês discutindo justamente essas questões em seu livro Teoria da interpretação, onde ele considera que se opõe a uma abordagem unidimensional da linguagem que leva em conta apenas o signo.

3 ARISTÓTELES, Da Interpretação, II, 16a 20.

4 Ibid., 16a 25. 5 HEIDEGGER, M. Die Grundbegriffe der Metaphysik: Welt, Endlichkeit, Einsamkeit, 1983, p. 446.

6 Ibid., p. 447.

7 GADAMER, H-G. Warheit und Methode,1986, p. 436.

8 Ibid., p. 450.

9 ARISTÓTELES. Política, [s.d.], II, 9.

10 HEIDEGGER, M. Brief über den Humanismus. In: Wegmarken, 1976.

11 BENVENISTE, E. Problemas de linguística geral I, 1995, pp. 60-67 e pp. 284-293. Nesses dois momentos do seu texto, encontramos o autor apontando para o caráter irredutível da linguagem humana, o fato de que ela não se apresenta sobremaneira entre os animais, assim como que ela tampouco deve ser pensada como um instrumento, pois este exigiria sua fabricação, o que não é o caso da linguagem, na medida em que ela não é passível de ser descoberta: "É um homem falando que encontramos no mundo, um homem falando com outro homem, e a linguagem ensina a própria definição do homem" (p. 285). 
12 MAUSS, M. Ensaio sobre a dádiva. In: Sociologia e Antropologia, 2003; LÉVI-STRAUSS. As estruturas elementares do parentesco, 2009; LACAN, J. Função e campo da palavra e da linguagem. In: Escritos, 1998. Idem, O Seminário, Livro 3, 2008. Nestas distintas escrituras encontramos os autores apontando para um mesmo núcleo argumentativo, qual seja: que o laço social encontra seu fundamento na dimensão Simbólica que, ao cruzar o elemento sexual - as relações de parentesco - com o campo da linguagem - palavra como ato -, acaba por criar, nesse momento preciso, num único lance de dados, o sistema da troca e o fato da regra. O ponto médio dessa relação, o que vem causar justamente a separação entre a natureza e a cultura é, pois, a proibição do incesto, que possui tanto um caráter universal, na medida em que opera em todas as sociedades humanas, quanto uma incidência no particular, pois cada um, a cada vez, respeita sua lei. Esta, por seu turno, é uma lei que não precisa ser escrita para operar e que de modo algum oferece exceção. Lévi-Strauss é preciso em suas palavras ao reconhecer que esta proibição é o dom por excelência. Nesses termos, vale ressaltar a importância da dádiva, visto que ela é uma espécie de moral "contratual" que obriga a receber e a retribuir o presente recebido. Para as comunidades arcaicas o presente devia circular da mesma forma como posteriormente circulará as moedas. Além disso, considerava-se a coisa doada parte do doador; sendo assim, havia um vínculo de direito em função de um vínculo de alma - e as coisas, nesses tempos primordiais, possuíam alma, ou seja, estavam ligadas ao homem por intermédio de sua voz, do sopro que fazia repercutir o som em uma forma significativa. Dessa forma, assim como para os gregos a noção de substância, a ousia, possuía um significado original que a ligava aos bens, de igual modo, posteriormente, para o direito romano a noção de res possuirá uma relação com o que está em causa, o que está em questão. As coisas fazem, por assim dizer, parte da família, são bens, de sorte que devem ser guardadas no interior da casa tanto quanto as pessoas, servindo, em momentos oportunos - celebrações, ritos, casamentos - à troca: "a res não deve ter sido, na origem, a coisa bruta e apenas tangível, o objeto simples e passível de transação que ela se tornou. Parece que a melhor etimologia é a que compara com a palavra sânscrita rah, ratih, dádiva, presente, coisa agradável. A res deve ter sido, antes de tudo, o que dá prazer a uma outra pessoa. Por outro lado, a coisa é sempre marcada, selada, com a marca da propriedade da família" (MAUSS, 2003, p. 270). Vale sublinhar ainda, que a dádiva, ao instituir um sistema de trocas por intermédio do presente configura a aliança, ou seja, o símbolo propriamente dito, representado pela figura do anel, sendo justamente este que se troca na ocasião do casamento. Esta união do que está separado é, portanto, o que queremos indicar propriamente com a noção do acordo. O que funda o acordo, porém, o que possibilita o presente, é um ausente, se tivermos como hipótese o interdito do incesto. A par disso, Lacan é contundente ao dizer que o homem fala somente porque o símbolo o fez homem, e que a Lei primordial, a proibição do incesto, 
deve ser reconhecida como idêntica a uma ordem de linguagem. Para o psicanalista francês, nenhum comportamento humano escapa às leis da fala, sendo justamente isto o que Freud procurou explicitar quando formulou o Édipo e o mito do parricídio em Totem e Tabu: “(...) a Lei está justamente ali desde o início, desde sempre, e a sexualidade humana deve se realizar por meio e através dela. Essa lei fundamental é simplesmente uma Lei de simbolização. É o que o Édipo quer dizer" (LACAN, 2008, p. 102). O não, nesse caso, é possibilidade para o sim.

13 Merleau-Ponty parece reconhecer justamente no espaço da fala uma dimensão que a precede, que está lá a marcar a sua possibilidade e que a ultrapassa em sua intenção de significar: “(...) precisamos considerar a fala antes de ser pronunciada, sobre o fundo do silêncio que a precede, que não cessa de acompanhá-la, e sem o qual ela nada diria; mais ainda, precisamos ser sensíveis aos fios de silêncio com que é tramado o tecido da fala". Cf. Merleau-Ponty, M. A prosa do mundo, 2002, p. 69.

14 DERRIDA, J. O círculo lingüístico de Genebra. In. Margens da filosofia, [s.d.], pp. 171- 192.

15 Nessa passagem vemos que Rousseau não trabalha com a distinção entre língua e linguagem, que, posteriormente, em Saussure será tão importante para o desenvolvimento de sua linguística.

16 Vale lembrar, a par disso, o quanto o tema da dialética do reconhecimento será importante para Hegel no capítulo IV de sua Fenomenologia do Espirito, a fim de poder pensar a passagem da consciência em-si para a autoconsciência. Esta, por seu turno, exige o reconhecimento do desejo do outro. 17 ROUSSEAU, J-J. Du contrat social, ou principes du droit politique, 1763,p. 17. Como podemos acompanhar nessa passagem do texto do filósofo francês, há algo que opera em todos os lugares, ainda que de maneira não expressa. Perguntamos, por isso, se não se trataria, neste caso, da noção do acordo que estaríamos aqui formulando, porquanto dispensa a expressão formal e, ainda assim, é observado em todos os lugares em que o homem se encontra.

18 ARISTÓTELES, Ética a Nicômacos, livro V, 7, 1134b.

19 AQUINO, T. Suma Teológica, II-IIae, q. 57, art. 1.

20 ARISTÓTELES, op. cit., 1, 1129a.

$21 \mathrm{Cf}$. Borges de Macedo, $O$ direito das gentes: entre o direito natural e o direito positivo, 2007.

22 AQUINO, T., op. Cit.

23 Ibid., q. 94, art. 2., p. 56324 Ibid. 